\title{
Een doelmatigheidsonderzoek naar de maatstaf van de gemiddelde consument
}

\author{
Bespreking van het proefschrift van mr. B.B. Duivenvoorde
}

Mr.dr.drs. C.M.D.S. Pavillon*

1 Een buitengewoon actueel proefschrift

De gemiddelde consument uit de Wet oneerlijke handelspraktijken stond in 2015 twee keer centraal in een arrest van de Hoge Raad. In de zaak tussen Stichting Loterijverlies en de Staatsloterij is de gemiddelde consument misleid. ${ }^{1}$ De advertentie van de Staatsloterij vermeldde 'elke maand 20 winnaars van $€ 100.000$,-', terwijl dit er in werkelijkheid maar ongeveer vier waren (de winnaars werden getrokken uit alle uitgegeven en niet slechts uit de verkochte loten). In de tweede zaak, ingesteld door de Stichting Misrekening tegen de ING Bank, is de gemiddelde consument juist niet misleid. ${ }^{2}$ De reclameboodschap van de ING Bank (toen nog Postbank geheten) luidde: 'Met een Toprekening ontvangt u maar liefst $4 \%$ rente. En als $\mathrm{u}$ nu een Toprekening opent krijgt $\mathrm{u}$ de eerste zes maanden zelfs 4,75\% rente.' Na zes maanden werd niet de geadverteerde $4 \%$ rente uitgekeerd, maar een lager percentage. In het eerste geval is de gemiddelde consument onjuist geïnformeerd over zijn winstkansen en had hij mogelijk een ander besluit over zijn deelname aan de loterij genomen indien hij de juiste informatie had gekregen. In het tweede geval is de gemiddelde consument niet misleid over het variabele karakter van de rentevergoeding op de geopende bankrekening. Hij had de aangeboden informatie, inclusief kleine lettertjes, gelet op de omstandigheden van het geval in redelijkheid zo moeten begrijpen dat de rekening niet aan een vast rentepercentage was gekoppeld.

Hoe komt het dat de gemiddelde consument in het eerste geval wel en in het laatste geval niet is misleid? Wat kenmerkt

\footnotetext{
Mr. dr. drs. C.M.D.S. Pavillon is universitair docent burgerlijk recht aan de Universiteit Leiden. Mijn dank gaat uit naar Thijs Beumers (Universiteit Leiden) voor zijn waardevolle suggesties.

1. HR 30 januari 2015, ECLI:NL:HR:2015:178, AA 2015, p. 784-793 m.nt. W.H. van Boom en C.M.D.S. Pavillon, NJ 2015/377 m.nt. S.D. Lindenbergh.

2. HR 1 mei 2015, ECLI:NL:HR:2015:1191 (art. 81 RO-zaak). Over de uitspraak in eerste aanleg (waarin de misleiding reeds is uitgesloten), zie A.G. Castermans, Misleidende omissie bij het aangaan van overeenkomsten. Reflexwerking van de regeling oneerlijke handelspraktijken, MvV 2011, afl. 7/8, p. 202-207.
}

de maatman uit de maximum harmoniserende Richtlijn oneerlijke handelspraktijken (hierna: Richtlijn OHP), die is omgezet in afdeling 6.3.3A van het Burgerlijk Wetboek (BW) ? ${ }^{3}$ Ligt de lat in de genoemde uitspraken te hoog (INGzaak) of juist te laag (Staatsloterij), gelet op de doelstellingen van de Richtlijn OHP: de bescherming van de consument, de goede werking van de interne markt en een gezonde concurrentie tussen bedrijven? Het helder afgebakende en strak opgebouwde rechtsvergelijkende proefschrift waarop Bram Duivenvoorde op 3 juli 2014 aan de Universiteit van Amsterdam promoveerde, is van onmiskenbare waarde bij het beantwoorden van deze vragen. $\mathrm{MvV}$ biedt mij de gelegenheid om dit in het licht van recente rechtspraak zeer relevante proefschrift, waarvan de handelseditie inmiddels bij Springer is verschenen, onder uw aandacht te brengen. ${ }^{4}$

Het proefschrift is als volgt opgebouwd. $\mathrm{Na}$ de inleiding schetst het eerste deel het Europeesrechtelijk kader van de gemiddelde consument: de Richtlijn OHP, de rechtspraak van het Hof van Justitie van de Europese Unie (hierna: HvJ) met betrekking tot de misleidingnorm en het merkenrecht alsmede de gezichtspunten die hieruit kunnen worden gedestilleerd. Het tweede deel bespreekt de nationale inkleuringen van de maatstaf van de gemiddelde consument (Duitsland, Engeland en Italië, gevolgd door een rechtsvergelijking). Het derde deel neemt de bescherming van de gemiddelde consument en de bescherming van de kwetsbare groepen consumenten onder de gedragswetenschappelijke loep. Het vierde deel gaat na in hoeverre de maatman uit de Richtlijn OHP verenigbaar is met de

3. Art. 6:193b lid 2 BW dient ter omzetting van de open norm van art. 5 lid 2 Richtlijn OHP en luidt: 'Een handelspraktijk is oneerlijk indien een handelaar handelt:

a. in strijd met de vereisten van professionele toewijding, en

b. het vermogen van de gemiddelde consument om een geïnformeerd besluit te nemen merkbaar is beperkt of kan worden beperkt, waardoor de gemiddelde consument een besluit over een overeenkomst neemt of kan nemen, dat hij anders niet had genomen.'

4. B.B. Duivenvoorde, The Consumer Benchmarks in the Unfair Commercial Practices Directive (diss. Amsterdam UvA), Cham: Springer 2015. 
door deze richtlijn gestelde doelen. Het onderzoek wordt afgesloten met een viertal aanbevelingen.

\section{De richtlijndoelstellingen en hun onderlinge verhouding}

In het proefschrift staat de vraag centraal in hoeverre de gemiddelde consument er als maatman in slaagt om de drie in paragaaf 2.3 door Duivenvoorde onderscheiden doelstellingen van de Richtlijn OHP te realiseren. Deze doelstellingen zijn: (1) de bescherming van de consument, (2) de vlotte werking van de interne markt en (3) de competitieve werking van deze markt. De onderlinge verhouding tussen de doelstellingen wordt helaas niet helemaal duidelijk en het geschetste normatieve raamwerk mist scherpte. Aan de ontstane verwarring is evenwel vooral de richtlijn zelf debet.

Gelet op haar rechtsbasis beoogt de Richtlijn OHP in de eerste plaats de goede werking van de interne markt te bevorderen en daarmee de welvaart te vergroten (art. 95 van het EGVerdrag (EG); thans art. 114 van het Verdrag betreffende de werking van de Europese Unie (VWEU)). De considerans onder randnummer 1 benadrukt dat maatregelen gebaseerd op art. $95 \mathrm{EG}$ (thans art. $114 \mathrm{VWEU}$ ) eveneens bijdragen aan de verwezenlijking van een hoog niveau van consumentenbescherming (art. 153 EG; thans art. 169 VWEU). De Richtlijn OHP weidt echter niet verder uit over de verhouding tussen de consumentenbeschermings- en internemarktdoelstelling. Dit leidt tot een enigszins verwarrend onderscheid tussen de beschermingsdoelstelling op zich, die niet is gelinkt aan de interne markt en hiermee kan conflicteren, en de beschermingsdoelstelling die ondergeschikt is aan de internemarktdoelstelling en ziet op de toename van het consumentenvertrouwen. $^{5}$

De plaatsing door Duivenvoorde van een derde doelstelling naast de consumentenbeschermings- en internemarktdoelstelling draagt ook enigszins bij aan de verwarring. Deze doelstelling - het bevorderen van marktcompetitie - volgt niet expliciet uit de Richtlijn OHP en wordt afgeleid uit de considerans en de Guidance van de Commissie ${ }^{6}$ bij de Richtlijn OHP. De bescherming van eerlijk opererende concurrenten is in mijn ogen, net als de harmonisatie van regelgeving en, tot op (on)zekere hoogte, de consumentenbescherming, vooral dienstig aan de overkoepelende internemarktdoelstelling. Er is gelet op de breedte van de tweede doelstelling zonder meer sprake van overlap tussen de verschillende doelstellingen. In de afsluitende aanbevelingen vraagt Duivenvoorde terecht om een nadere verduidelijking van de richtlijndoelstellingen en van hun onderlinge relatie.

5. Duivenvoorde stelt dat de ratio achter de bescherming van de kwetsbare consument meer een sociale dan een economische is. In mijn optiek is deze aandacht voor de zwakkere marktdeelnemers ook zonder meer bedoeld als een bijdrage aan de interne markt.

6. Europese Commissie, Guidance on the Implementation/Application of Directive 2005/29/EC on Unfair Commercial Practices, SEC(2009) 1666.

\section{De maatstaf van de gemiddelde consument}

De gemiddelde consument is de maatstaf aan de hand waarvan de oneerlijkheid van een handelspraktijk wordt vastgesteld of, zo u wilt, de bril waardoor het misleidende karakter van commerciële communicatie wordt beoordeeld. ${ }^{7}$ Duivenvoorde staat aan het begin van zijn onderzoek uitgebreid stil bij de driekoppige maatman uit de Richtlijn OHP. De 'gemiddelde consument' is een 'redelijk geïnformeerde, omzichtige en oplettende consument'. Bij de inkleuring van deze maatstaf kunnen maatschappelijke, culturele en taalkundige factoren in acht worden genomen, zo blijkt uit de rechtspraak van het $\mathrm{HvJ}$ en de considerans bij de richtlijn (randnummer 18). Deze gemiddelde consument wordt niet apart gedefinieerd in art. 2 van de Richtlijn OHP (en afdeling 6.3.3A BW bevat evenmin een definitie).

De Richtlijn OHP voorziet ook in een tweetal 'afwijkende' maatmannen. Deze maatmannen zijn nader op de specifieke context toegesneden maatmannen. Ten eerste bestaat de mogelijkheid om bij de vaststelling van de oneerlijkheid van een praktijk uit te gaan van 'het gemiddelde lid van een specifieke groep waarop de handelaar zich richt'. Ten tweede kan als maatman worden gehanteerd 'het gemiddelde lid van een specifieke groep waarvan de handelaar redelijkerwijs kan voorzien dat die groep wegens hun geestelijke of lichamelijke beperking, hun leeftijd of goedgelovigheid bijzonder vatbaar is voor de handelspraktijk of voor het onderliggende product'. Onder bepaalde omstandigheden, indien een handelspraktijk op een bepaalde groep is gericht of in geval van een voorzienbare, bijzondere kwetsbaarheid van een groep consumenten, kan dus worden afgeweken van de maatstaf van 'de redelijk geïnformeerde, omzichtige en oplettende consument'. Deze bijzondere maatmannen worden expliciet in art. 6:193a lid 2 BW genoemd.

Het proefschrift biedt vervolgens een helder overzicht van de rechtspraak van het HvJ inzake de 'gemiddelde consument'. Vooropstaat dat deze rechtspraak uitgaat van de redelijk geïnformeerde consument. ${ }^{8}$ Verdere aangrijpingspunten zijn schaars, de invulling en het gewicht van de aangereikte gezichtspunten (sociale, culturele en taalkundige factoren, empirisch onderzoek) zijn onbepaald. Bij de toepassing van de twee bijzondere maatmannen biedt de rechtspraak van het HvJ ook bijzonder weinig houvast. Uit de rechtspraak van het $\mathrm{HvJ}$ volgt dat de maatman eerder een normatief dan een empirisch concept vormt. Met andere woorden: de sterkte van de bril hoeft niet door een meting te worden bepaald. ${ }^{9}$ En de

7. Er dient een onderscheid te worden gemaakt tussen de vaststelling van de maatman en de vaststelling van de oneerlijkheid van een handelspraktijk. De maatman is als het ware het beslissende gezichtspunt bij de oneerlijkheidstoets.

8. Rechtspraak met betrekking tot het merkenrecht legt de lat iets lager, zo betoogt Duivenvoorde, maar het is onduidelijk of deze kan worden doorgetrokken naar het handelspraktijkenrecht.

9. De rol die empirisch onderzoek kan spelen bij de vaststelling van de verwachtingen ten aanzien van het gedrag van het drietal maatmannen blijkt niet duidelijk uit deze rechtspraak, zie hierna par. 4 . 
normtoepasser (rechter of toezichthouder) beschikt slechts over open geformuleerde en soms tegenstrijdige aanwijzingen bij het slijpen van de glazen. De maatman is het beslissende criterium bij de toetsing aan de open misleidingnorm en zonder handvatten ligt een geharmoniseerde toepassing van die norm niet in de lijn der verwachting. De harmonisatiedoelstelling wordt, zo onderstreept Duivenvoorde terecht, bemoeilijkt door het gebrek aan sturing door de Richtlijn OHP en het HvJ. ${ }^{10}$

In het rechtsvergelijkend deel van het proefschrift wordt aan de hand van grondig rechtspraakonderzoek aangetoond dat de nationale invulling van de maatstaf uiteenloopt en dat van harmonisatie geen sprake is. ${ }^{11}$ Zo maakt de Duitse rechter bij het hanteren van de Europese maatstaf ruimte voor een minder oplettende en kritische consument als de gegeven informatie objectief onjuist is. Duivenvoorde sluit niet uit dat deze contextgebonden minder kritische maatman in strijd komt met de Richtlijn OHP. Ook de verwachtingen van de Engelse en Italiaanse rechters ten aanzien van de gemiddelde consument zijn in grote lijnen beduidend minder hooggespannen dan die van de Europese rechter. Duivenvoorde merkt op dat de onderzochte nationale inkleuringen meer afwijken van de in de Europese rechtspraak geschetste maatman dan van elkaar. Toch zijn er wel degelijk verschillen tussen de in de onderzochte lidstaten gehanteerde maatstaven en dan met name wat betreft de toepassing van de twee bijzondere maatmannen.

Het contrasteffect was wellicht iets groter geweest, ware Nederland in het onderzoek betrokken. Er is in Nederland op de keper beschouwd weinig aandacht voor een minder oplettende consument. Van de gemiddelde consument wordt verwacht dat hij bereid is zich in de aangeboden informatie te verdiepen en deze te lezen in het licht van de marktomstandigheden. Dit blijkt uit de Dexia-uitspraak ${ }^{12}$ en uit bovengenoemd arrest betreffende de door de Postbank geadverteerde rente. ${ }^{13}$ De verwachtingen ten aanzien van de gemiddelde financiële consument zijn daarmee redelijk hooggegrepen. Hij is zonder meer rationeel: de informatie die hij krijgt - ook de kleine lettertjes - neemt hij door alvorens een besluit over de overeenkomst te nemen. ${ }^{14}$ Voorts is hij in staat om deze informatie te begrijpen en in een bepaalde context te plaatsen. In de Staatsloterij-zaak wordt in dit opzicht iets minder verwacht van de rationele maatman. Hij hoeft niet te verwachten dat de geadverteerde prijzen niet allemaal worden uitgekeerd, volgt geen

10. Ik bereikte in mijn dissertatie een vergelijkbare conclusie. C.M.D.S. Pavillon, Open normen in het Europees consumentenrecht. De oneerlijkheidsnorm in vergelijkend perspectief (diss. Groningen), Deventer: Kluwer 2011 .

11. Het is voor de lezer zeer prettig dat de originele tekst wordt weergegeven alsmede de Engelse vertaling hiervan.

12. HR 5 juni 2009, ECLI:NL:HR:2009:BH2815 (Dexia).

13. Andere bekende voorbeelden zijn HR 10 juli 2009, ECLI:NL:HR: 2009:BI3408 (Cashbackactie) en HR 27 november 2009, ECLI:NL:HR: 2009:BH2162 (World online).

14. Dit besluit moet (zeer) ruim worden opgevat: HvJ EU 19 december 2013, C-281/12, ECLI:EU:C:2013:859 (Trento Sviluppo), r.o. 36. a contrario-redenering bij het lezen van de spelvoorwaarden en realiseert zich niet hoe klein de winstkansen daadwerkelijk zijn. $^{15}$

\section{Gedragstheoretische inzichten en empirische vaststelling van de gemiddelde consument}

Het meest interessante en vernieuwende deel van het proefschrift betreft de toetsing van de maatman aan gedragstheoretische inzichten. Dit deel brengt eerder verricht empirisch onderzoek in beeld, aan de hand waarvan verschillende aannames betreffende de gemiddelde consument worden ontkracht. Zo wordt in de Richtlijn OHP en door het HvJ ten onrechte verondersteld dat de consument rationeel is en dat vastgesteld kan worden wat een gemiddelde consument doet. In het verlengde hiervan wordt volgens Duivenvoorde van de onjuiste veronderstelling uitgegaan dat kwetsbare consumenten in categorieën kunnen worden ingedeeld.

De uit het EU-recht afgeleide aannames worden weerlegd door middel van argumenten ontleend aan bestaand gedragstheoretisch onderzoek. Het promotieonderzoek van Duivenvoorde strekt niet tot het falsificeren van dit onderzoek, maar vormt een doelmatigheidsonderzoek van de maatman, in het licht van de richtlijndoelstellingen. Dat Duivenvoorde zelf geen gedragswetenschappelijk onderzoek heeft verricht, heeft als nadeel dat hij de beperkingen van empirisch onderzoek niet aan den lijve heeft ondervonden. ${ }^{16}$ Het proefschrift vormt een normatief onderzoek waarin argumenten worden ontleend aan andere disciplines zonder dat Duivenvoorde zich verdiept in de aan deze disciplines onderliggende methodes. Dat is jammer, omdat met name de aannames betreffende de mogelijkheid om een gemiddelde (al dan niet kwetsbare) consumentmaatstaf vast te stellen nauw samenhangen met de bij deze vaststelling gehanteerde methodologie. Tegelijkertijd is deze keuze gelet op de opzet van het onderzoek, de omvang en veelzijdigheid van het gedragsonderzoek en de benodigde knowhow ook zonder meer verdedigbaar. In de inleiding wordt deze keuze kort toegelicht.

Het proefschrift is zeer informatief en brengt convergerende uitkomsten van gedragsonderzoek aan het licht, namelijk dat er op verschillende punten discrepantie bestaat tussen de fictieve maatman en op empirie gestoelde gedragstheorieën. Deze

15. Zie hierover W.H. van Boom \& C.M.D.S. Pavillon, Meer kans in de Staatsloterij?, annotatie bij HR 30 januari 2015, ECLI:NL:HR: 2015:178, AA 2015, afl. 10, p. 789. Deze uitspraak is ook bijzonder voor zover zij de gemiddelde consument behalve rationele (een grove inschatting van zijn winstkansen) ook minder doordachte motieven toedicht om over te gaan tot een 'besluit' (wanneer deze motieven de overhand krijgen, kan overigens de conclusie worden getrokken dat van misleiding in de zin van de richtlijn geen sprake is - de informatie leidt dan immers niet tot een verkeerd 'besluit'). Voor een minder rationele consument is in de Richtlijn OHP en de rechtspraak van het HvJ, zoals uiteengezet door Duivenvoorde, weinig ruimte.

16. Te denken valt aan de representativiteit van het onderzoek en de formulering van de vragen. Ook rijst de vraag of bij de selectie van bestaande onderzoeksresultaten niet voorbij is gegaan aan onderzoek waarin de aannames juist - tot op bepaalde hoogte - worden bevestigd. 
discrepantie gaat, zo stelt Duivenvoorde, ten koste van de beschermingsdoelstelling: de gemiddelde consument is te rationeel en de twee overige maatstaven vormen geen effectief correctiemechanisme omdat kwetsbaarheid zich niet in groepen laat vatten en sterk situatiegebonden is. De Richtlijn $\mathrm{OHP}$ en het $\mathrm{HvJ}$ gaan uit van een van de realiteit losgezongen zogenaamd gemiddelde consument. ${ }^{17}$

Deze uitkomst roept vragen op ten aanzien van de houdbaarheid van de 'feitelijke waarderingen' 18 van de feitenrechter, zoals die zijn gemaakt in de twee aangehaalde recente uitspraken van de Hoge Raad. Deze waarderingen betreffen enerzijds de keuze voor een bepaalde maatman (het slijpen van de brillenglazen) en anderzijds de vaststelling van de misleiding (het kijken door die bril). ${ }^{19}$ Beide vragen - wie is de gemiddelde consument, en is hij misleid? - zijn in een concrete zaak onlosmakelijk met elkaar verbonden. De manier waarop de gemiddelde consument de informatie percipieert en begrijpt, definieert immers kenmerken als de mate van oplettendheid en geïnformeerdheid. Om die kenmerken bij te stellen zou idealiter sprake zijn van een empirische terugkoppeling. De misleidingtoets vormt echter een overwegend normatieve exercitie. Het adjectief feitelijk is in dit opzicht dus enigszins misleidend. ${ }^{20}$ Feitelijk, in de zin van empirisch, zijn de rechterlijke oordelen betreffende de aan de in de concrete zaak gehanteerde fictieve maatman toe te dichten perceptie doorgaans niet. De vaststelling van de percepties van de fictieve maatman in de voorliggende zaak wordt niet als een bewijskwestie gezien. ${ }^{21}$ Aangeboden bewijs waarin die perceptie empirisch is onderzocht, wordt meestal terzijde gelaten. ${ }^{22}$ Evenmin schakelt de rechter zelf een deskundige in. De rechterlijke oordelen zijn wel feitelijk voor zover de rechter de misleiding beoordeelt aan de hand van de door partijen aangevoerde stellingen en feiten (en feiten van algemene bekendheid). Maar hij kijkt naar deze feiten door een normatieve bril.

17. Zie hierover ook B.B. Duivenvoorde, De 'gemiddelde consument' als rationele actor, WPNR (2010) 6849, p. 533 e.v., W.F. van Raaij, Het beeld van de consument in het privaatrecht empirisch getoetst, in: W.H. van Boom, I. Giesen \& A.J. Verheij (red.), Capita civilologie. Handboek empirie en privaatrecht, Den Haag: Boom Juridische uitgevers 2013, p. 27 e.v. en B.B. Duivenvoorde, De gemiddelde consument als standaard bij misleiding. Een kritische blik vanuit de gedragswetenschappen, in: W.H. van Boom, I. Giesen \& A.J. Verheij (red.), Capita civilologie. Handboek empirie en privaatrecht, Den Haag: Boom Juridische uitgevers 2013, p. 147 e.v.

18. HR 30 januari 2015, ECLI:NL:HR:2015:178, r.o. 4.1. Zie ook concl. A-G Wissink voor de Staatsloterij-zaak, ECLI:NL:PHR:2014:2812, r.o. 3.40 en voor de ING-zaak, ECLI:NL:PHR:2015:314, r.o. 3.36.

19. De nationale rechter beschikt, gelet op de mogelijkheid om sociale, culturele en taalkundige factoren mee te laten wegen, empirisch onderzoek te verrichten of gebruik te maken van de bijzondere maatmannen, over een zekere beoordelingsruimte bij de beantwoording van de vraag of de gemiddelde consument in het voorliggende geval door de hem ter beschikking gestelde informatie is misleid.

20. Van Boom \& Pavillon 2015, p. 789.

21. Concl. A-G Wissink voor de Staatsloterij-zaak, ECLI:NL:PHR: 2014:2812, r.o. 3.40 .

22. Van getuigenbewijs wordt door het hof in de Staatsloterij-zaak opgemerkt: 'niet valt in te zien wat getuigen zouden kunnen verklaren over de wetenschap, opvattingen en gedragingen van de "gemiddelde consument" die immers een fictieve entiteit is (rov. 4.16)'.
Benadrukt zij dat de Nederlandse aanpak in overeenstemming is met de Richtlijn OHP. De considerans bij de richtlijn vermeldt dat de gemiddelde consument geen 'statistisch criterium' vormt, maar dat de rechter zo nodig wel een beroep kan doen op empirische gegevens (randnummer 18). Ook het HvJ, zo benadrukt Duivenvoorde in hoofdstuk 3, verkiest in zaken met betrekking tot misleidende handelspraktijken, bij het toedichten van kenmerken aan de maatman, een normatieve boven een empirische benadering, al hinken sommige uitspraken op twee gedachten. ${ }^{23}$ Het HvJ geeft niet duidelijk aan onder welke omstandigheden dergelijk onderzoek uitkomst zou kunnen of zelfs moeten bieden. In hoofdstuk 3 van het proefschrift wordt het merkenrecht als uitzondering genoemd, omdat hierin van een soepelere consumentmaatstaf wordt uitgegaan. In dat veld is door de Nederlandse rechter juist regelmatig empirisch onderzoek gebruikt. ${ }^{24}$ Voor het buiten beschouwing laten van empirische gegevens valt in het licht van deze ervaring echter wel wat te zeggen. Het is niet eenvoudig om dergelijke gegevens op hun waarde te schatten, gelet op de mogelijke tekortkomingen van dergelijk onderzoek (representativiteit, gestelde vragen, enzovoort). Onduidelijk is ook wat juridisch relevante percentages vormen.

\section{Toetsing van de gemiddelde consument aan de richtlijndoelstellingen en aanbevelingen}

Duivenvoorde komt tot de weinig opbeurende maar niet geheel onverwachte conclusie dat de maatman tekortschiet in het bereiken van de drie richtlijndoelstellingen. Het is volgens hem echter niet zo dat de ene doelstelling ten koste van de andere wordt gerealiseerd. Dit is opmerkelijk, omdat tussen de beschermings- en internemarktdoelstelling een zekere spanning bestaat. Duivenvoorde wijst erop dat de internemarkt- en eerlijkecompetitiedoelstellingen om een maatstaf vragen die niet te veel, maar juist ook niet te weinig bescherming biedt aan de consument. Op Europees niveau is echter een strenge maatstaf geïntroduceerd en de kwetsbare maatman vervult zijn corrigerende rol niet naar behoren.

Duivenvoorde besluit zijn onderzoek met een viertal concrete aanbevelingen die een aanzet vormen tot nadere reflectie. Deze vier aanbevelingen dienen welbeschouwd vooral de beschermingsdoelstelling (wat niet verbaast in het licht van de gedragstheoretische inzichten). Dit geldt zeker voor de eerste aanbeveling: het afstand nemen van de maatman zoals geschetst door het $\mathrm{HvJ}$ omwille van een meer flexibele beoordeling waarin oog is voor een breed scala aan factoren, zoals hoeveel consumenten er zijn misleid, in welke mate zij zijn misleid, hoeveel consumenten er voordeel hebben van de praktijk en in welke mate, welke kosten de consument respectievelijk de

23. HvJ EG 16 januari 1992, C-373/90, Jur. 1992, p. I-131 (Nissan) en HvJ EU 18 november 2010, C-159/09, ECLI:EU:C:2010:696 (Lidl/Vierzon), r.o. 49 verwijzen bijv. naar wat een aanzienlijk deel van consumenten feitelijk zou hebben gedaan.

24. J.J.C. Kabel, Rechter en publieksopvattingen: feit, fictie of ervaring? (oratie Amsterdam UvA), 2005, p. 5; P.A.C.E. van der Kooij, De maatman in het merkenrecht, in A.G. Castermans e.a. (red.), De maatman in het burgerlijk recht (BWKJ 24), Deventer: Kluwer 2008, p. 287. 
ondernemer zich moet getroosten om misleiding te voorkomen, enzovoort. Op de overige twee doelstellingen (interne markt en mededinging) is de impact van deze multifactoroneerlijkheidstoets minder duidelijk. Deze ambivalentie vloeit voort uit de onduidelijkheid ten aanzien van het precieze beschermingsniveau dat past bij de internemarkt- en eerlijkecompetitiedoelstellingen. ${ }^{25}$ Duivenvoorde stelt dat de keuze voor de mee te wegen gezichtspunten kan variëren al naar gelang de nagestreefde doelstelling(en) en uitleg hiervan. Mij komt voor dat een dergelijke toets tot mogelijk nog grotere uitlegverschillen zal leiden dan thans het geval is, en dat deze onvoorspelbaarheid bedrijven ervan kan weerhouden over de grens te handelen.

Interessant is na te gaan om welke benadering - feitelijk of normatief - de voorgestane custom-made oneerlijkheidstoets vraagt. Van Boom ${ }^{26}$ opperde in 2005 reeds dat empirisch onderzoek een oplossing vormt om de fictieve en echte consument naar elkaar toe te laten groeien en de gemiddelde consument de bescherming te bieden die hij daadwerkelijk nodig heeft. ${ }^{27}$ De door Duivenvoorde voorgestelde gezichtspunten vragen inderdaad om nader onderzoek naar het gedrag van de consument. Reeds verricht onderzoek kan hiervoor als basis dienen (net als in het proefschrift), maar ook het op eigen initiatief van de rechter uitzetten van enquêtes en opinieonderzoek wordt genoemd in hoofdstuk 12. In welke mate en in welke gevallen dergelijk feitelijk onderzoek wenselijk is, wordt helaas niet duidelijk. Evenmin gaat het proefschrift in op de voorwaarden waar dit type onderzoek aan zou moeten voldoen. Gelet op de internemarktdoelstelling is van belang dat de spelregels voor het aanwenden én uitvoeren van dergelijk onderzoek worden gestroomlijnd en voldoende voorspelbaar zijn.

De tweede aanbeveling strekt tot het verhelderen van de doelstellingen en van hun onderlinge samenhang (zie hiervoor par. 2). De invulling en het gewicht van de door hem voorgestelde gezichtspunten hangen als gezegd af van de prevalerende doelstelling(en). Ook vraagt Duivenvoorde om duidelijke handvatten voor de praktijk bij de inkleuring van de open normen uit de Richtlijn OHP. Het Guidance-document van de Europese Commissie geeft hier deels gehoor aan. Het is echter niet toereikend en soms zelfs tegenstrijdig, aldus Duivenvoor-

25. Zij komt de eerlijkecompetitiedoelstelling ten goede voor zover deze inhoudt dat de consument, om goed beslagen ten ijs te komen, voldoende informatie moet krijgen. $\mathrm{Zij}$ gaat ten koste van deze doelstelling indien te veel van de handelaar wordt gevraagd in termen van informatievoorziening. De eerste aanbeveling dient de internemarktdoelstelling voor zover deze gebaat is bij een hoog beschermingsniveau, maar staat deze doelstelling echter in de weg als wordt aangenomen dat de interne markt een eenvormige maatstaf vergt.

26. W.H. van Boom, Een gewaarschuwd mens, TvC 2005, afl. 5, p. 173-174.

27. Overigens is empirisch onderzoek niet altijd in het voordeel van de consument. In de Staatsloterij-zaak zou empirisch onderzoek er zeer wel op kunnen wijzen dat van misleiding in de zin van een merkbare beïnvloeding van het economisch gedrag van de consument geen sprake is. de. Het $\mathrm{HvJ}$ heeft recent een aantal definities ${ }^{28}$ en praktijken op de zwarte lijst ${ }^{29}$ verduidelijkt, maar er is omwille van de harmonisatiedoelstelling meer en vooral meer gedetailleerde houvast nodig bij de invulling van de open normen. Deze aanbeveling onderschrijf ik zonder meer. De nadere sturing door het HvJ hangt echter niet slechts af van zijn bereidheid om prejudiciële vragen van een duidelijk antwoord te voorzien, maar ook van de bereidheid van nationale rechters om vragen te stellen, die bovendien zo zijn geformuleerd dat hierop een gericht antwoord kan worden gegeven.

Ten derde wordt aanbevolen de keuze voor maximale harmonisatie bij de Richtlijn OHP te heroverwegen. Deze aanbeveling komt vooral de consumentenbescherming ten goede: het is lidstaten bij minimumharmonisatie toegestaan om extra beschermende maatregelen te treffen. Het terugdraaien van een reeds bepaald harmonisatieniveau is bij mijn weten nog nooit voorgekomen. Bij de Commissie lijkt de gedachte van volledige harmonisatie van consumentenrecht na het debacle met de Richtlijn consumentenrechten ook niet aan populariteit te hebben ingeboet, getuige de meest recente richtlijnvoorstellen ten behoeve van de digitale interne markt. ${ }^{30}$

Duivenvoorde acht het onwenselijk dat het tekort aan sturing, bescherming en flexibiliteit dat het gebruik van de Europese maatman kenmerkt, zich ook op andere deelterreinen van het consumentenrecht voordoet. Aan zijn vierde en laatste aanbeveling - het niet verder uitbreiden van de maatman uit de Richtlijn OHP naar andere consumentenbeschermende instrumenten - is op Europees niveau echter inmiddels voorbijgegaan. Uit het Kásler-arrest volgt dat de maatstaf van een 'normaal geïnformeerde en redelijk omzichtige en oplettende gemiddelde consument' bepalend is bij de toetsing aan de transparantie-eis uit art. 5 van de Richtlijn oneerlijke bedingen (art. 6:238 lid $2 \mathrm{BW}$ ). Het arrest legt de lat op het eerste gezicht overigens vrij hoog voor de gebruiker van algemene voorwaarden. Deze voorwaarden moeten niet slechts taalkundig en grammaticaal begrijpelijk zijn, maar de gemiddelde consument ook duidelijke criteria verschaffen die hem in staat stellen om de economische gevolgen van de toepassing van het beding te voorzien. ${ }^{31}$ De vraag is evenwel hoe streng deze

28. De handelspraktijk is nader gedefinieerd in HvJ EU 16 april 2015, C-388/13, ECLI:EU:C:2015:225 (Nemzeti). Ook 'individuele' praktijken (het verschaffen van informatie aan een individuele consument) vallen hieronder.

29. Duivenvoorde noemt in zijn proefschrift het Purely creative-arrest betreffende art. 6:193h onder h BW (punt 31 van de lijst): HvJ EU 18 oktober 2012, C-428/11, ECLI:EU:C:2012:651, TvC 2013, afl. 2 m.nt. B.B. Duivenvoorde. Zie ook, over het piramidespel (art. 6:193g onder n BW; punt 14 van de lijst), HvJ EU 3 april 2014, C-515/12, ECLI:EU:C: 2014:211 (4finance), TvC 2014, afl. 5 m.nt. B.B. Duivenvoorde.

30. Op 9 december 2015 verschenen twee richtlijnvoorstellen gebaseerd op volledige harmonisatie: een 'on certain aspects concerning contracts for the supply of digital content', $\operatorname{COM}(2015) 634$ final, en een 'on certain aspects concerning contracts for the online and other distance sales of goods', $\operatorname{COM}(2015) 635$ final. Ook de nieuwe Richtlijn pakketreizen gaat uit van maximumharmonisatie.

31. HvJ EU 30 april 2014, C-26/13, ECLI:EU:C:2014:282, NJ 2014/355 m.nt. MRM (Kásler), r.o. 74. 


\section{Maandblad} Vermogensrecht

transparantieplicht wordt opgevat, anders gezegd: hoe snel de gemiddelde consument in staat wordt geacht de economische gevolgen van de toepassing van een beding te begrijpen. ${ }^{32}$ In Nederland is de gemiddelde consument volgens de parlementaire geschiedenis van afdeling 6.5.2B BW ter omzetting van de Richtlijn consumentenrechten ook de maatstaf bij de beoordeling van de duidelijkheid van de door deze richtlijn verplicht gestelde contractuele informatie. ${ }^{33}$ Langzaam maar zeker sluipt de 'gemiddelde consument' het contractenrecht binnen en de Richtlijn OHP laat het verbintenissenrecht, in weerwil van het in art. 3 lid 2 van de richtlijn bepaalde, dus allesbehalve onverlet. ${ }^{34}$

\section{Tot slot}

De aanbevelingen van Duivenvoorde zijn gericht tot de Europese instellingen en dan met name de richtlijngever (Commissie, Raad en Europees Parlement). Het in het Engels geschreven proefschrift zet in op veranderingen op het Europese niveau. Tegelijkertijd biedt het ook bruikbare handvatten aan de nationale jurist die een blik wil werpen op de doelstellingen van de Richtlijn OHP, de invulling van de maatman in andere lidstaten en de verhelderende inzichten uit de gedragswetenschappen. Het proefschrift is vooral interessant voor de Nederlandse praktijkjurist - rechter of toezichthouder - die de maatman toepast. Hij wordt zich bewust van twee zaken die in de rechtspraktijk nogal eens van de radar verdwijnen: de beperkte aansluiting van de fictieve maatstaf op de werkelijkheid en de Europese dimensie van die maatstaf.

Tijd om terug te komen op de in de inleiding genoemde uitspraken. De kleurrijke, van vele voorbeelden voorziene dissertatie van Duivenvoorde dwingt ons deze uitspraken in het perspectief van de door de Richtlijn OHP gestelde doelstellingen te bezien. En dit is een buitengewoon nuttige exercitie. De ING-uitspraak legt net als in de rechtspraak van het HvJ de lat vrij hoog, wat ten koste gaat van de beschermingsdoelstelling. En het valt evenzeer te betwijfelen of de internemarktdoelstelling hiermee wordt gediend: de eisen die de Nederlandse rechter stelt aan de gemiddelde consument wijken af van de eisen die in andere lidstaten aan hem worden gesteld en het vertrouwen van de financiële consument is buitengewoon laag. Wellicht had in deze zaak meer aandacht moeten worden besteed aan de Europese ratio achter de misleidingnorm. Bij de Staatsloterij-zaak werd in lijn met de aanbevelingen van Duivenvoorde juist enige afstand genomen van de strikte, bijna niet te misleiden maatman, met als gevolg dat de loterijbranche haar

32. In Rb. Midden-Nederland 16 september 2015, ECLI:NL:RBMNE: 2015:6873, NJF 2015/465, r.o. 2.4 en Rb. Midden-Nederland 4 november 2015, ECLI:NL:RBMNE:2015:8258 was de gemiddelde consument hier niet toe in staat. In Hof Arnhem-Leeuwarden 17 november 2015, ECLI:NL:GHARL:2015:8705, r.o. 3.5 juist wel.

33. Kamerstukken II 2012/13, 33520, 3, p. 48. Dat deze consument de te hanteren maatstaf is, staat niet met zoveel woorden in de richtlijn, maar zou kunnen worden afgeleid uit overweging 34 van de considerans.

34. Zie hierover M. Durovic, The Subtle Europeanization of Contract Law: The Case of Directive 2005/29/EC on Unfair Commercial Practices, European Review of Private Law 2015, afl. 5, p. 715-749. praktijken heeft herzien en het vertrouwen van spelers heeft herwonnen. ${ }^{35}$ De opbloeiende interne markt van loterijen is hier zonder meer bij gebaat. ${ }^{36}$ Maar loterijen blijven toch vooral een nationale aangelegenheid en de impact van deze uitspraak op de interne markt blijft dus enigszins beperkt.

35. Overigens gebeurde dit vrijwel meteen nadat de misleidende praktijk naar buiten kwam. Zo wordt verklaard dat het aantal verkochte loten niet is afgenomen. Zie r.o. 4.15 van het hof.

36. Voorbeelden van Europese loterijen zijn: Eurojackpot en Euro Millions. 